\title{
NANOPARTICLES: AN OVERVIEW OF THE PREPARATION METHODS FROM PREFORMED POLYMERS
}

\author{
BARBARA STELLA (*), ALESSANDRO MARENGO, SILVIA ARPICCO
}

SUNTO. - Le nanoparticelle polimeriche hanno numerose potenziali applicazioni in campo biomedico, poiché possono essere impiegate come sistemi di trasporto di farmaci e/o a scopo diagnostico. L'incorporazione nelle nanoparticelle polimeriche può prevenire la degradazione del principio attivo, controllarne la velocità e il grado di rilascio e aumentarne la concentrazione al sito bersaglio. Tuttavia, le caratteristiche chimico-fisiche delle nanoparticelle possono modificare l'attività del principio attivo incorporato. Al fine di ottenere un sistema di trasporto che risponda a specifiche necessità terapeutiche e/o diagnostiche, è fondamentale la scelta del metodo di preparazione adatto; essa è dettata dalle caratteristiche chimico-fisiche sia del polimero sia del principio attivo, dalla via di somministrazione, da considerazioni di ordine regolatorio e dalle caratteristiche chimico-fisiche e morfologiche che le nanoparticelle dovranno avere. Per la preparazione di nanoparticelle polimeriche sono adottate due principali strategie: l'uso di polimeri preformati e la polimerizzazione di monomeri. In questo articolo sono presentati i metodi più utilizzati che partono da polimeri preformati; in particolare, sono descritte cinque tecniche: la nanoprecipitazione, il salting-out, l'emulsione diffusione, l'emulsione evaporazione e la doppia emulsioneevaporazione del solvente.

$$
* * *
$$

ABSTRACT. - Polymer nanoparticles have many potential applications in biomedical field, since they can be used as drug delivery systems and/or for diagnostic purposes. The encapsulation into polymer nanoparticles may prevent drug degradation, control the rate and extent of release, and deliver a higher concentration of the active molecule to a desired organ/tissue. Nevertheless, the physicochemical characteristics of nanoparticles may greatly influence the activity of the encapsulated molecule. To obtain a suitable drug delivery system the choice of the nanoparticle preparation

(*) Dipartimento di Scienza e Tecnologia del Farmaco, Università degli Studi di Torino, Italia. E-mail: barbara.stella@unito.it 
method is a crucial key. The selection of a specific technique is generally determined by the physicochemical characteristics of both polymer and drug, the delivery route, regulatory restrictions, and the desired physicochemical and morphological parameters of the nanoparticles. Two main strategies are employed for the preparation of polymer nanoparticles: the dispersion of preformed polymers and the polymerization of monomers. This review focuses on most commonly used methods that start from preformed polymers, and, in particular, on five techniques: nanoprecipitation, salting-out, emulsification diffusion, emulsification evaporation, and double emulsion solvent evaporation.

\section{INTRODUCTION}

Nowadays, innovative technologies, such as colloidal drug carriers, are devoted to overcome most common obstacles encountered in traditional drug delivery, such as low bioavailability, poor stability, bitter taste of active agents. The application of nanotechnology in medicine have led to a new concept called nanomedicine. In this field many colloidal drug carriers have been developed, in particular nanoparticles. The term "nanoparticles" designates solid submicronic particles formed of acceptable materials (e.g. polymers, lipids, etc.) able to encapsulate and deliver active agents. Nanoparticles include both nanospheres and nanocapsules: nanospheres are matrix systems in which the drug is dispersed within the polymer, throughout the particle, while nanocapsules are vesicular systems in which the drug is located in an inner cavity surrounded by a thin polymer layer (Fig. 1).

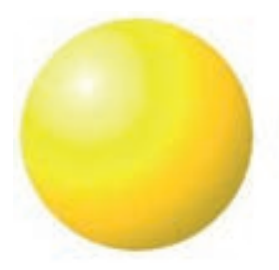

nanosphere

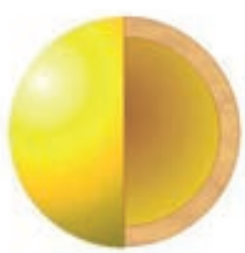

nanocapsule

Fig. 1. Schematic representation of a nanosphere and a nanocapsule.

Polymer nanoparticles are one of the most promising approaches to deliver therapeutic and diagnostic agents. Indeed, thanks to the 
wide range of available materials and preparation methods, polymer nanoparticles are attractive carriers for an efficient drug delivery by preventing drug degradation, controlling the rate and extent of release, and delivering a higher concentration of the active molecule to a desired organ/tissue, thus lowering toxic effects. Polymers should be biocompatible and biodegradable. Commonly used polymers for nanoparticle preparation include poly(lactic acid) (PLA), poly (glycolic acid) (PGA), poly(lactic-co-glycolic acid) (PLGA), poly( $\varepsilon$-caprolactone) (PCL), and poly(alkyl cyanoacrylates) (PACA) (Lai et al., 2014). Concerning encapsulated drugs, not only lipophilic but also hydrophilic molecules can be loaded into polymer-based nanoparticles, starting from low molecular weight molecules until proteins and nucleic acids (Arpicco et al., 2016).

There are many methods available to prepare drug-loaded polymer nanocarriers; to select the appropriate technique the physicochemical characteristics of both polymer and drug must be taken into account to ensure a good interaction between the active molecule and the nanoparticle matrix (Miladi et al., 2014). Two main strategies are employed for the preparation of polymer nanoparticles: the dispersion of preformed polymers and the polymerization of monomers (Rao and Geckeler, 2011). Generally, methods utilizing preformed polymers are preferred because these techniques avoid the presence of toxic residues as compared with methods based on polymerization reactions.

This review focuses on the five most commonly used nanoparticle manufacturing methods starting from preformed polymers, notably nanoprecipitation, salting-out, emulsification diffusion, emulsification evaporation, and double emulsion solvent evaporation. The nanoparticle preparation methods here presented are all bottom-up approaches, which are based on self-assembly using small building blocks to assemble a larger particle. All these techniques involve an organic solution (typically the solvent phase) containing the nanoparticle components and an aqueous solution (typically the non-solvent phase) containing stabilizers that will constitute the dispersion medium (Quintanar-Guerrero et al., 1998). Each preparation method is described in details in the following sections and advantages and disadvantages for all techniques have been summarized in Tab. 1 . 
Tab. 1. General advantages and disadvantages of techniques used for nanoparticle preparation from preformed polymers.

\begin{tabular}{|c|c|c|}
\hline Method & Advantages & Disadvantages \\
\hline Nanoprecipitation & $\begin{array}{l}\text { Simple, fast } \\
\text { Non-highly toxic solvents used } \\
\text { No high shear stress required } \\
\text { Reproducible, easy to scale up }\end{array}$ & $\begin{array}{l}\text { Mostly limited to the } \\
\text { encapsulation of hydrophobic } \\
\text { drugs } \\
\text { Low polymer concentration in } \\
\text { the organic phase }\end{array}$ \\
\hline Salting-out & $\begin{array}{l}\text { No high shear stress required } \\
\text { Applicable to heat sensitive drugs } \\
\text { High entrapment of lipophilic } \\
\text { drugs } \\
\text { Reproducible, easy to scale up }\end{array}$ & $\begin{array}{l}\text { Possible incompatibility } \\
\text { between the salts and the } \\
\text { drugs } \\
\text { Extensive washing steps } \\
\text { Mostly limited to the } \\
\text { encapsulation of hydrophobic } \\
\text { drugs }\end{array}$ \\
\hline $\begin{array}{l}\text { Emulsification } \\
\text { diffusion }\end{array}$ & $\begin{array}{l}\text { Applicable to heat sensitive } \\
\text { drugs } \\
\text { High entrapment of lipophilic } \\
\text { drugs } \\
\text { Reproducible, easy to scale up }\end{array}$ & $\begin{array}{l}\text { Required concentration of } \\
\text { final formulation } \\
\text { Low entrapment of } \\
\text { hydrophilic drugs } \\
\text { Long processing times }\end{array}$ \\
\hline $\begin{array}{l}\text { Emulsification } \\
\text { evaporation }\end{array}$ & $\begin{array}{l}\text { High entrapment of lipophilic } \\
\text { drugs } \\
\text { Tunable size of nanoparticles }\end{array}$ & $\begin{array}{l}\text { Low entrapment of } \\
\text { hydrophilic drugs } \\
\text { High shear stress required } \\
\text { Difficult to scale up }\end{array}$ \\
\hline Double emulsion & $\begin{array}{l}\text { Possibility to encapsulate both } \\
\text { hydrophilic and lipophilic drugs }\end{array}$ & $\begin{array}{l}\text { Large and non-uniform } \\
\text { nanoparticles } \\
\text { High shear stress required } \\
\text { Two-step process } \\
\text { Difficult to scale up }\end{array}$ \\
\hline
\end{tabular}

\section{NANOPRECIPITATION}

The nanoprecipitation technique, also known as solvent diffusion or solvent displacement, was first developed by Fessi et al. (1989). It is a onestep process that allows the instantaneous and reproducible formation of monodisperse nanoparticles (Lepeltier et al., 2014). In this process the polymer and the drug must be first dissolved in a water miscible organic solvent (the most common used are ethanol and acetone). This organic mixture is then added to an aqueous solution (non-solvent of the polymer) under moderate stirring causing nanoparticles with a well-defined size and a narrow distribution to precipitate instantly due to solvent diffusion into 
the aqueous matrix. Rapid diffusion of the solvent into non-solvent phase results in the decrease of interfacial tension between the two phases, which leads to the formation of small droplets. The solvent is then evaporated at reduced pressure and an aqueous suspension of nanoparticles is thus obtained. For nanocapsules preparation, the same method is used, except that an oil is added to the organic solution of the polymer in order to form an inner oily cavity (Couvreur et al., 2002).

Particle formation process includes three basic steps: particle nucleation, molecular growth, and aggregation. The rate of each step determines the particle size. Ideally, operating conditions should allow a high nucleation rate strongly dependent on supersaturation and low growth rate (Lepeltier et al., 2014; Lince et al., 2008).

Commonly used polymers are biodegradable polyesters, especially PCL, PLA, PLGA, and PACA (Lepeltier et al., 2014).

In this method nanoparticle size is strongly affected by several operating parameters, such as the polymer concentration, polymer's molecular weight, solvent or solvent mixtures used, the organic phase to nonorganic phase ratio, stirring speed, and the addition of a stabilizer.

To further improve the reproducibility of the nanoprecipitation technique and make it more convenient for industrial applications, some devices have been proposed, such as a membrane contactor (Charcosset and Fessi, 2005) and confined impinging jets reactors (CIJR) (Lince et al., 2011). CIJR are small passive mixers in which very fast turbulent mixing of the solvent (e.g. acetone) and of the antisolvent (water) occurs, under controlled conditions. CIJR can be operated continuously and the process can easily be scaled up.

The nanoprecipitation technique is simple, fast, reproducible, scalable and no high shear stress is required. The drawbacks of this method are low polymer concentration in the organic phase and low loading efficiency for hydrophilic drugs because of the hydrophobicity of nanoparticle matrix. Nevertheless, it is possible to increase the loading of these molecules following several strategies (Arpicco et al., 2016).

\section{SALTING-OUT}

The salting-out technique is based on two phases that are mixed together to form an oil-in-water emulsion (Mendoza-Muñoz et al., 2012). The oil phase is a solution of a polymer and an active compound 
in a water miscible solvent, while the aqueous phase is a solution or gel containing a colloidal stabilizer and a high concentration of a saltingout agent that hinders the solvent diffusion. The resulting oil-in-water $(\mathrm{o} / \mathrm{w})$ emulsion is then diluted with an amount of pure water that lowers the concentration of the salting-out agent below a threshold, enabling the organic solvent to rapidly diffuse into the aqueous phase and leading to the formation of nanoparticles. Then, the organic solvent is removed by evaporation at reduced pressure. Repeated washing steps are then needed to remove the salting-out agent. Similarly to what happens during nanoprecipitation, in the salting-out procedure interfacial turbulences are generated when the initial emulsion is diluted with water, causing violent spreading because of the sudden mutual miscibility of the solvents. Nanometric droplets of solvent, torn from the interface, are rapidly stabilized by the surfactant agent until the complete diffusion of the solvent inducing the polymer aggregation in the form of nanoparticles (Quintanar-Guerrero et al., 1998).

The organic solvents need to be totally miscible with water and the most common are acetone, ethanol, methanol, and acetonitrile. Many polymers have been tested for nanoparticle preparation by this technique, such as PLA, PGA, PLGA, PCL (Allémann et al., 1993); Zweers et al., 2006). Concerning the salting-out agent, for acetonewater phase separation the most common agents are magnesium chloride, calcium chloride, magnesium acetate, and sucrose. Colloidal stabilizers are added to the aqueous phase to reduce the particle size (Galindo-Rodriguez et al., 2004).

The salting-out technique does not require immiscible and toxic solvents, it is applicable to heat sensitive drugs, and no high shear stress is required; moreover, it is a versatile, scalable and reproducible method. Nevertheless, salts could be incompatible with drugs, extensive nanoparticles washing steps are required after obtaining the suspensions and hydrophilic drugs have low encapsulation efficiency.

\section{EMULSIFICATION DIFFUSION}

This technique was developed starting from the salting-out procedure in order to avoid the use of highly concentrated salt solutions, and, consequently, to reduce the purification time. The emulsification diffusion method involves a first step, in which the partially water miscible 
solvent and water are mutually saturated. Then, the polymer and the drug (and oil for nanocapsules) are dissolved in the saturated solvent and the stabilizers are dissolved in water. Next, a stable o/w emulsion is obtained by dispersing the organic phase in the aqueous phase, generally in a 1:2 volume ratio. The final step involves the addition to the system of a sufficient amount of water to break the emulsion, causing the solvent diffuse into the external phase and prompting the aggregation of the materials (polymer and drug) in nanoparticles (QuintanarGuerrero et al., 2012). The emulsification of the organic phase in water produces emulsion droplets that will form several nanoparticles at a one-to-ten ratio (Quintanar-Guerrero et al., 1997). Stabilizers (e.g. poloxamer 188 and poly(vinyl alcohol) (PVA)) can be present in the water amount added in the last step.

In this method the polymer concentration, the mixing speed and the stabilizers have an effect on particle size.

Different materials can be used, such as polymers (e.g. PLA, PCL, PLGA) (Quintanar-Guerrero et al., 1998) and lipids (Noriega-Peláez et al., 2011). Among the organic solvents, ethyl acetate and methyl ethyl ketone are frequently used.

The emulsification diffusion method is a reproducible and scalable technique that allows the incorporation of thermosensitive drugs. One of the most common disadvantages in this method is the poor encapsulation efficiency of hydrophilic molecules due to drug partitioning into the continuous aqueous phase when polymer desolvation is induced to form the particles. Moreover, the concentration of final formulation is required. Finally, this method needs longer processing times and greater control of the preparative variables compared with the nanoprecipitation method.

\section{EMULSIFICATION EVAPORATION}

Emulsification evaporation was the first method proposed for the preparation of polymer nanoparticles (Vanderhoff et al., 1979). It involves a first step in which the polymer and the active ingredient are dissolved in a volatile water immiscible organic solvent. Dichloromethane and chloroform were frequently used, but now ethyl acetate is preferred to address residual solvent toxicity concerns. Then, the solvent solution is emulsified with an aqueous phase containing a 
stabilizer to form an o/w emulsion. A high shear stress (e.g. by ultrasonication or homogenization) is then applied to break the emulsion droplets into even smaller ones (Nava-Arzaluza et al., 2012; Lai et al., 2014). The size of the nanoparticles that will be formed is directly related to the dimension of the droplets. The organic solvent is then evaporated by continuous stirring at room temperature or under reduced pressure causing polymer precipitation and nanoparticle formation. The emulsification evaporation method differs from the emulsification diffusion technique in the type of solvent (immiscible $v$ s partially water miscible) and in the higher stress applied to the emulsion.

Nanoparticle size is affected not only by the strong forces and temperature applied to the emulsion, but also by: a) the polymer concentration and molecular weight; b) the drug/polymer proportion; c) the phases viscosity; d) the ratio of organic solvent to aqueous solvent; and e) concentration and type of stabilizers utilized (e.g. PVA, poloxamer 127, poloxamer 188, and polysorbate 80) (Nava-Arzaluza et al., 2012).

Commonly used polymers to produce nanoparticles by emulsification evaporation include PLA, PGA, PLGA, ethylcellulose, cellulose acetate phthalate, PCL, poly $(\beta$-hydroxybutyrate), and PACA (Sovan et al., 2011; Julienne et al., 1992; Peracchia et al., 1998).

Advantages of the emulsification evaporation method are the high encapsulation efficiency for hydrophobic drugs, good yield, reproducibility, and tunability. The major drawbacks are the poor efficiency in the incorporation of hydrophilic molecules that are retained in the aqueous phase during the emulsion formation process and the need for high shear mixing (with heat production) to obtain small emulsion droplets.

\section{Double EMUlSiON}

Double emulsions are also called "emulsions of emulsions" and they can encapsulate both hydrophobic and hydrophilic molecules (separately or simultaneously) due to their complex structure: in double emulsions the droplets of dispersed phase contain small compartments of another dispersed phase (Garti and Bisperink, 1998). There are two common types of double emulsions: water-oil-water $(\mathrm{w} / \mathrm{o} / \mathrm{w})$ and oilwater-oil (o/w/o). Hydrophilic substances are generally difficult to be encapsulated in drug carriers because of rapid drug partitioning into the external aqueous phase. To this aim, w/o/w emulsions have been 
developed and used for many drugs (Iqbal et al., 2015). Practically, for the double emulsion procedure an oil phase, water and stabilizers are needed. For w/o/w emulsion the water soluble drug is added within the inner aqueous phase $\left(\mathrm{w}_{1}\right)$ of the emulsion and it is then dispersed into the oil phase containing lipophilic emulsifier; in the second step the primary emulsion is dispersed into outer aqueous phase $\left(\mathrm{w}_{2}\right)$ containing hydrophilic emulsifier (Garti and Bisperink, 1998; Schuch et al., 2013).

A commonly used double emulsion method for preparation of micro- and nanoparticles is double emulsion solvent evaporation technique. In this method, after the homogenization of the aqueous phase containing the water soluble drug $\left(\mathrm{w}_{1}\right)$ and the oil phase (o) (generally a solvent containing the polymer/lipophilic drug) to form the primary emulsion $\left(\mathrm{w}_{1} / \mathrm{o}\right)$, a second step provides the emulsification with the outer aqueous phase $\left(\mathrm{w}_{2}\right)$ containing appropriate stabilizer to form double emulsion $\left(\mathrm{w}_{1} / \mathrm{o} / \mathrm{w}_{2}\right)$. Formation of particulate dispersion is followed by evaporation of the organic solvent and hardening of the polymer encapsulating the drug.

Generally, for this technique polyesters are used, such as PLA, PLGA, PCL (Montiel-Eulefi et al., 2014; Iqbal et al., 2014); PVA is commonly added, as stabilizer (Rizkalla et al., 2006).

Many common drugs have been loaded into nanoparticles by double emulsion process; in particular, also hydrophilic molecules, such as proteins and nucleic acids, have been successfully encapsulated by this technique (Iqbal et al., 2015).

Despite the advantage of encapsulating both hydrophobic and hydrophilic molecules, some difficulties are linked to double emulsion formulation; in particular, the stability of these thermodynamically unstable systems is a key issue to be managed by the addition of suitable stabilizers. Another drawback is due to high shear force used for homogenization that can damage biomolecules, thus leading to loss of activity. Moreover, double emulsions may contain large and non-uniform particles. Finally, it is a two-step process and, thus, it requires a long preparation process and it is difficult to scale up.

\section{CONCLUSIONS}

Polymer nanoparticles offer a great potential for drug delivery since they may be tailor made for specific purposes. Nevertheless, the 
selection of the appropriate approach for nanoparticle preparation is a crucial key to achieve specific needs. This paper reported the most commonly used methods for the preparation of polymer nanoparticles from preformed polymers; specific features, operating conditions, advantages and disadvantages for each procedure have been highlighted to allow the choice of the suitable manufacturing method.

\section{ACKNOWLEDGEMENTS}

A.M. is a $\mathrm{PhD}$ student in receipt of a fellowship from the Doctoral Program in "Sciences and Innovative Technologies" of the University of Torino.

\section{REFERENCES}

Allémann E, Leroux JC, Gurny R, Doelker E. In vitro extended release properties of drug-loaded poly(DL-lactic acid) nanoparticles produced by a salting-out procedure. Pharm Res 1993;10:1732-1737.

Arpicco S, Battaglia L, Brusa P, Cavalli R, Chirio D, Dosio F et al. Recent studies on the delivery of hydrophilic drugs in nanoparticulate systems. J Drug Deliv Sci Tec 2016;32:298-312.

Charcosset C, Fessi H. A new process for drug loaded nanocapsules preparation using a membrane contactor. Drug Dev Ind Pharm 2005;31:987-992.

Couvreur P, Barratt G, Fattal E, Legrand P, Vauthier C. Nanocapsule technology: a review. Crit Rev Ther Drug Carrier Syst 2002;19:99-134.

Fessi H, Puisieux F, Devissaguet JP, Ammoury N, Benita S. Nanocapsule formation by interfacial polymer deposition following solvent displacement. Int J Pharm 1989; 55:R1-R4.

Galindo-Rodriguez S, Allémann E, Fessi H, Doelker E. Physicochemical parameters associated with nanoparticle formation in the salting-out, emulsification-diffusion, and nanoprecipitation methods. Pharm Res 2004;21:1428-1439.

Garti N, Bisperink C. Double emulsions: progress and applications. Curr Opin Colloid Interface Sci 1998;3:657-667.

Iqbal M, Valour JP, Fessi H, Elaissari A. Preparation of biodegradable PCL particles via double emulsion evaporation method using ultrasound technique. Colloid Polym Sci 2014;293:861-873.

Iqbal M, Zafar N, Fessi H, Elaissari A. Double emulsion solvent evaporation techniques used for drug encapsulation. Int J Pharm 2015;496:173-190.

Julienne MC, Alonso MJ, Gomez Amoza JL, Benoit JP. Preparation of poly $(d, l$ lactide/glycolide) nanoparticles of controlled particle size distribution: application of experimental designs. Drug Dev Ind Pharm 1992;18:1063-1077. 
Lai P, Daeara W, Löbenbergb R, Prennera EJ. Overview of the preparation of organic polymeric nanoparticles for drug delivery based on gelatine, chitosan, poly(d,l-lactide-co-glycolic acid) and polyalkylcyanoacrylate. Coll Surf B Biointerf 2014;118: 154-163.

Lepeltier E, Bourgaux C, Couvreur P. Nanoprecipitation and the "Ouzo effect": application to drug delivery devices. Adv Drug Deliv Rev 2014;71:86-97.

Lince F, Marchisio DL, Barresi AA. Strategies to control the particle size distribution of

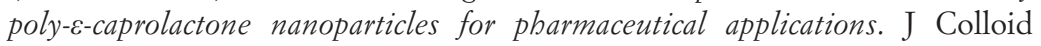
Interface Sci 2008;322:505-515.

Lince F, Bolognesi S, Marchisio DL, Stella B, Dosio F, Barresi AA et al. Preparation of poly(MePEGCA-co-HDCA) nanoparticles with confined impinging jets reactor: experimental and modeling study. J Pharm Sci 2011;100:2391-2405.

Mendoza-Muñoz N, Quintanar-Guerrero D, Allémann E. The impact of the salting-out technique on the preparation of colloidal particulate systems for pharmaceutical applications. Rec Pat Drug Del Form 2012;6:236-249.

Miladi K, Ibraheem D, Iqbal M, Sfar S, Fessi H, Elaissari A. Particles from preformed polymers as carriers for drug delivery. EXCLI J 2014;13:28-57.

Montiel-Eulefi E, Jara F, Toro C, Garcés M, Leal P. Cytotoxic effect of double emulsion (W/O/W) $\mathrm{CuSO}_{4}$ loaded PLA nanoparticles on MKN-45 gastric adenocarcinoma cell line. Int J Morphol 2014;32:61-69.

Nava-Arzaluza MG, Piñón-Segundob E, Ganem-Ronderoa A, Lechuga-Ballesteros D. Single emulsion-solvent evaporation technique and modifications for the preparation of pharmaceutical polymeric nanoparticles. Rec Pat Drug Del Form 2012;6: 209-223.

Noriega-Peláez EK, Mendoza Muñoz N, Ganem-Quintanar A, Quintanar-Guerrero D. Optimization of the emulsification and solvent displacement method for the preparation of solid lipid nanoparticles. Drug Dev Ind Pharm 2011;3:160-166.

Peracchia MT, Vauthier C, Desmaële D, Gulik A, Dedieu JC, Demoy M et al. Pegylated nanoparticles from a novel methoxypolyethylene glycol cyanoacrylate bexadecyl cyanoacrylate amphiphilic copolymer. Pharm Res 1998;15:550-556.

Quintanar-Guerrero D, Allémann E, Doelker E, Fessi H. A mechanistic study of the formation of polymer nanoparticles by the emulsification-diffusion technique. Colloid Polym Sci 1997;275:640-647.

Quintanar-Guerrero D, Allémann E, Fessi H, Doelker E. Preparation techniques and mechanisms of formation of biodegradable nanoparticles from preformed polymers. Drug Dev Ind Pharm 1998;24:1113-1128.

Quintanar-Guerrero D, Zambrano-Zaragoza M, Gutiérrez-Cortez E, Mendoza-Muñoz N. Impact of the emulsification-diffusion method on the development of pharmaceutical nanoparticles. Rec Pat Drug Del Form 2012;6:184-194.

Rao JP, Geckeler KE. Polymer nanoparticles: Preparation techniques and size-control parameters. Prog Polym Sci 2011;36:887-913.

Rizkalla N, Range C, Lacasse FX, Hildgen P. Effect of various formulation parameters on the properties of polymeric nanoparticles prepared by multiple emulsion method. J Microencapsulation 2006;23:39-57. 
Schuch A, Deiters P, Henne J, Köhler K, Schuchmann HP. Production of W/O/W (water-in-oil-in-water) multiple emulsions: droplet breakup and release of water. J Colloid Interface Sci 2013;402:157-164.

Sovan LP, Utpal J, Manna PK, Mohanta GP, Manavalan R. Nanoparticle: an overview of preparation and characterization. J App Pharm Sci 2011;1:228-234.

Vanderhoff JW, El-Aasser MS, Ugelstad J. Polymeric emulsification process. US4177177. 1979.

Zweers ML, Engbers GH, Grijpma DW, Feijen J. Release of antirestenosis drugs from poly(ethylene oxide)-poly(DL-lactic-co-glycolic acid) nanoparticles. J Control Rel 2006;114:317-324. 